\title{
25 Research Square \\ Tailoring Growth of MOF199 on Hierarchical Surface of Bamboo and Its Antibacterial Property
}

\section{Minglei Su}

International center for bamboo and rattan https://orcid.org/0000-0001-9435-8246

Rong Zhang ( $\nabla$ zhangrong@icbr.ac.cn )

International Center for Bamboo and Rattan

Jingpeng Li

China National Bamboo Research Center

Xiaobei Jin

International center for bamboo and rattan

Xiaofeng Zhang

International Center for Bamboo and Rattan

Daochun Qin

International Center for Bamboo and Rattan

\section{Research Article}

Keywords: Bamboo, MOF, Tailoring growth, Pretreatment, Antibacterial

Posted Date: March 10th, 2021

DOl: https://doi.org/10.21203/rs.3.rs-263128/v1

License: (c) (i) This work is licensed under a Creative Commons Attribution 4.0 International License.

Read Full License

Version of Record: A version of this preprint was published at Cellulose on October 22nd, 2021. See the published version at https://doi.org/10.1007/s10570-021-04265-z. 


\section{Abstract}

Bamboo, as a fast-grown forest resource, could be functionalized by metal-organic frameworks (MOF) with various potential applications. However, the stability of MOF immobilized on bamboo surface remains to be improved. In this work, MOF199, as known as HKUST-1, was in situ anchoring on moso bamboo via regulating pretreatment of bamboo and a green two-step synthesis route. The two-step synthesis route could be completed under room temperature and both precursor solutions can be reused. The results indicated that, with the collaboration of delignification and carboxymethylation pretreatment of bamboo, a dense and well-dispersed MOF199 coating was successfully synthesized, the adhesion between MOF and bamboo surface was also improved. Besides, the quantity and size of MOF199 on bamboo can be tailored by adjusting the carboxyl groups of pretreated bamboo and the concentration of copper nitrate solution. More importantly, results show that the formation of carboxyl-copper (II) complex served as nucleation sites for the growth of MOF199 crystals is the key to prepare uniform MOF layers. The growth of MOF199 endow bamboo with good antibacterial activity against $E$. coli. This method provides a facile and practical strategy for designing MOF coated woody materials.

\section{Introduction}

Metal-organic frameworks (MOF) have attracted considerable attention due to their high porosity and surface area, flexible tunability, and well-defined architecture (Duan et al. 2019a). And it has been used in antibacterial systems, gas storage, heavy metal adsorption and catalysis fields (Nasruddin et al. 2020). Because of MOFs are mostly in powder form and difficult to handling with, so the deposition/composition of various MOF onto/into various substrates is necessary to expand the potential applications of these functional materials (Jin et al. 2013; Ren et al. 2015).

According to previous reports, MOF have been successfully synthesized onto different bio-based materials, such as cellulose fiber (Ma et al. 2018; Wang et al. 2015), wool fabric (Lis et al. 2019), cotton fabric (Abdelhameed et al. 2016; Emam et al. 2016), which all have loose and porous structures and facilitate the attachment of MOF (Duan et al. 2018). In cellulose materials, various efforts have been made to improve the attachment between MOF and the substrate by introducing carboxyl groups, such as carboxymethylation (Duan et al. 2019a), TEMPO (2,2,6,6-tetramethylpiperidine-1-oxyl radical)-mediated oxidation (Duan et al. 2019b), hydrogen peroxide oxidation (Abdelhameed et al. 2016). Woody materials consist of lignin and carbohydrates (cellulose and hemicellulose), such as wood and bamboo. They possess hierarchical porous structure and superior mechanical properties along with its light weight, which offers an ideal scaffold to manufacture high-performance composite materials (Chen et al. 2020; He et al. 2020). However, in the cell wall of woody plant, lignin tightly wrapped the cellulose and hemicellulose, because of the lack of active functional group in lignin and inconsistent lignin amounts on the cell wall, it is difficult for the uniform surface modification on woody materials (Guo et al. 2016; Ma et al. 2020). Compared with the lignin and hemicellulose, cellulose is easier to be modified because of the active primary alcohol in its repeating glucose structure (Abdelhameed et al. 2016). Therefore, delignification could expose cellulose and hemicellulose, which is conducive to the later 
carboxymethylation treatment and improve MOF attachment (Chen et al. 2020). However, it is still challenging to control the size and quantity of MOF on the surface of such bio-materials, which have significant impacts on the performance of composites (Wyszogrodzka et al. 2016).

Bamboo has been widely used as interior decorative materials and daily necessities, such as flooring, furniture, fabrics and paper, especially in Asia (Li et al. 2017). However, the main drawback of bamboo is that it is susceptible to bacteria and fungi, as for its rich nutrients content (Li et al. 2019; Zhang et al. 2020). Recently, MOF/woody composites materials have been used in several antibacterial applications (Su et al. 2019). MOF199, which consist of copper (II) ions and 1,3,5-benzentricarboxylic acid (BTC), has been proved to with powerful antibacterial activity on textile fabric (Ma et al. 2018; Wang et al. 2015). The copper (II) in MOF199 can denature proteins and fatty acids in bacterial cell membrane or change transmembrane potential, leading to cell rupture and death (Wyszogrodzka et al. 2016). In our previous work, we successfully deposited MOF199 on the surface of moso bamboo, and the obtained materials exhibited good antibacterial activity against both Staphylococcus aureus (S. aureus) and Escherichia coli (E. coli) (Su et al. 2019). However, due to the weakness of physical deposition between MOF and bamboo, MOF easily disengaged from the bamboo surface and limited its application.

In this article, MOF199 was in situ synthesized on moso bamboo at room temperature in a two-step synthesis route, as shown in Schematic 1. To improve the attachment of MOF on bamboo, pretreatment including carboxymethylation and delignification were carried out collaboratively. The growth of MOF coating on bamboo surface was well tailored through the successive immersion of the copper nitrate and BTC solution. The size and quantity of MOF199 on bamboo surface could be easily controlled and crystal growth mechanism was studied. And the antibacterial properties of MOF coated bamboo were analyzed. The study provides a new strategy for fabricating MOF-functionalized woody materials.

\section{Experiments}

\subsection{Materials and Chemicals}

Moso bamboo (Phyllostachys edulis) of four-year-old was obtained from Yongan, Fujian, China. The bamboo samples were cut into the dimension of $20 \mathrm{~mm} \times 25 \mathrm{~mm} \times 4 \mathrm{~mm}(\mathrm{~L} \times \mathrm{T} \times \mathrm{R})$ and were ultrasonic cleaned with deionized water for $30 \mathrm{~min}$, then vacuum dried at $60^{\circ} \mathrm{C}$ for $24 \mathrm{~h}$ before use.

Copper nitrate trihydrate $\left(\mathrm{Cu}\left(\mathrm{NO}_{3}\right)_{2} \cdot 3 \mathrm{H}_{2} \mathrm{O}\right)$, , 1,3,5-benzentricarboxylic acid $\left(\mathrm{BTC}, \mathrm{C}_{6} \mathrm{H}_{3}(\mathrm{COOH})_{3}\right)$, sodium chlorite $\left(\mathrm{NaClO}_{2}, 80 \%\right)$ were purchased from Aladdin Chemistry Co. Ltd (Shanghai, China). Sodium hydroxide $(\mathrm{NaOH})$, chloroacetic acid sodium salt $\left(\mathrm{ClCH}_{2} \mathrm{COONa}\right)$, acetic acid $\left(\mathrm{CH}_{3} \mathrm{COOH}\right)$, anhydrous ethanol $\left(\mathrm{C}_{2} \mathrm{H}_{5} \mathrm{OH}\right)$, triethylamine $\left(\left(\mathrm{C}_{2} \mathrm{H}_{5}\right)_{3} \mathrm{~N}\right)$ and $\mathrm{N}$, $\mathrm{N}$-dimethylformamide $\left(\mathrm{DMF},\left(\mathrm{CH}_{3}\right)_{2} \mathrm{NCHO}\right)$ were purchased from Beijing Chemical Works (Beijing, China). All these chemicals were used as received without further purification and deionized (DI) water was used in the whole process.

\subsection{Pretreatment of bamboo}


Three batches of pretreated bamboo were obtained by delignification and carboxylation separately and collaboratively, the experimental process is as follows:

Delignification: The natural bamboo samples were initially delignified by dipping in an aqueous solution of $1 \mathrm{wt} \%$ sodium chlorite $\left(\mathrm{pH}=4.6\right.$, acetic acid) at $100^{\circ} \mathrm{C}$ for $1 \mathrm{~h}$. Then the delignified bamboo samples were rinsed with distilled water and dried in vacuum oven for $24 \mathrm{~h}$ and marked as DB.

Carboxymethylation: The carboxymethylation of bamboo was carried out through condensation reaction between cellulose and chloroacetate salt in the presence of sodium hydroxide (Laurila et al. 2015; Wang et al. 2012). Natural bamboo and DB samples were respectively submerged in sodium hydroxide solution $(1 \mathrm{~mol} / \mathrm{L}$ ) for $30 \mathrm{~min}$ at room temperature, then the samples were respectively soaking in $1 \mathrm{~mol} / \mathrm{L}$ aqua solution of chloroacetate salt for $30 \mathrm{~min}$ and dried at $85^{\circ} \mathrm{C}$ for $30 \mathrm{~min}$. Later, the samples were respectively acidified with $2 \mathrm{~g} / \mathrm{L}$ aqueous solution of acetic acid for $10 \mathrm{~min}$ at room temperature. Finally, the pretreated samples were washed with distilled water to remove the excess precursor and drying in vacuum oven for $24 \mathrm{~h}$, and marked as carboxymethylated bamboo (CB), delignified and carboxymethylated bamboo (DCB).

\subsection{In-situ growth of MOF199 on bamboo}

The synthesis of MOF199 on bamboo was performed in a two-step route according to previous literature with some slight adjustments (Lange and Obendorf 2015). In a typical synthesis, copper nitrate trihydrate $(17.9 \mathrm{~g})$ was dissolved in $250 \mathrm{~mL}$ mixed solvent $\mathrm{DMF} /$ ethanol/water $(\mathrm{v} / \mathrm{v} / \mathrm{v}=1: 1: 1)$ as solution $\mathrm{A}, \mathrm{BTC}$ $(10.4 \mathrm{~g})$ was dissolved in $250 \mathrm{ml}$ of the same mixed solvent $D M F /$ ethanol/water $(\mathrm{v} / \mathrm{v} / \mathrm{v}=1: 1: 1)$ and 1.25 $\mathrm{mL}$ of triethylamine was added, as solution B. Four kinds of bamboo samples (natural bamboo, DB, CB and $\mathrm{DCB}$ ) were respectively submerged in solution $\mathrm{A}$ overnight at room temperature. After that, the samples were taken out and wiped off the excess liquid attached, then submerged in solution $B$ for another $24 \mathrm{~h}$. Finally, the as-prepared four kinds of MOF199 coated bamboo were washed by ethanol and water and named as MOF199/B, MOF199/DB, MOF199/CB, MOF199/DCB, respectively.

\subsection{Tailoring crystal size of MOF199}

$4.48,8.95,17.9$ and $35.8 \mathrm{~g}$ of copper nitrate trihydrate were dissolved in $250 \mathrm{ml}$ solvent solution of $\mathrm{DMF} /$ ethanol/water ( $\mathrm{v} / \mathrm{v} / \mathrm{v}=1: 1: 1)$, respectively. The DCB samples were immersed in four concentrations of copper nitrate solution overnight. Then, after removed the excess liquid attached, samples were put into solution B for another $24 \mathrm{~h}$, respectively. Finally, the obtained samples were washed by ethanol and water and named as MOF199/DCB-1, MOF199/DCB-2, MOF199/DCB-3, MOF199/DCB-4, respectively.

\subsection{Alternative synthesis of MOF199 on bamboo}

The DCB samples were first immersed in solution B overnight. Then the samples were taken out to wipe off the excess liquid attached and put into the solution $A$ for another $24 \mathrm{~h}$. After that, the obtained sample were washed by ethanol and water and named as rMOF199/DCB.

\subsection{Characterization}


Micro-structure investigations were performed using scanning electron microscopy (SEM, XL30ESEMFEG, PHILIPS, Netherlands) at $10 \mathrm{kV}$. Elemental analysis was detected by an energy-dispersive X-ray spectroscopy (EDS, quantax400, Bruker). FTIR spectrums were collected with a Thermo iS10 FT-IR spectrometer (Nicolet, USA) using an attenuated total reflection (ATR) module, at a scanning number of 64 and spectral resolution of $4 \mathrm{~cm}^{-1}$, ranging from $600 \mathrm{~cm}^{-1}$ to $4000 \mathrm{~cm}^{-1}$. The crystalline structures of the samples were identified by X-ray diffraction (XRD, X' Pert PRO MPD, Nalytical, Netherlands) using $\mathrm{Cu}$ $\mathrm{Ka}$ radiation at a scan rate of $2 \%$ min and generator voltage of $40 \mathrm{kV}$, ranging from $5^{\circ}$ to $80^{\circ}$. X-ray photoelectron spectroscopy (XPS, Thermo ESCALAB 250Xi, USA) was used to analysis the elemental valence, which were obtained using an ESCALab MKII X-ray photoelectron spectrometer with Al Ka X-ray radiation as the excitation source.

\subsection{Antibacterial test}

The antibacterial properties of MOF coated bamboo against E. coli (ATCC 25922) were performed according to the Japan Industry Standard JIS Z $2801-2000$ and Chinese Industry Standard QB/T 2591 - 2003. On the surface of each sample, $0.2 \mathrm{~mL}$ of the $E$. coli bacteria suspension with the concentration of 5.0-10.0 $\times 10^{5} \mathrm{CFU} / \mathrm{ml}$ was added, and each sample was covered by polyethylene films $(18 \times 18$ $\left.\mathrm{mm}^{2}\right)$, respectively. Then the inoculated samples were incubated for $24 \mathrm{~h}\left(37 \pm 1^{\circ} \mathrm{C}, \mathrm{RH}>90 \%\right)$. After incubation, each sample and polyethylene film were rinsed by $20 \mathrm{ml}$ eluent (with $0.5 \%$ Tween 80 ), the dilutions of each sample were collected and 20 ul of each dilution was inoculated respectively on nutrient broth, and cultured for another $24 \mathrm{~h}$ at $37 \pm 1^{\circ} \mathrm{C}$. Finally, the number of bacteria colony of each sample was calculated according to Chinese Standard GB 4789.2-201623 and the actual data as CFU/piece are presented. The antibacterial test for each sample were repeated three times.

The calculation formula of antibacterial rate is as follows:

$$
A R(\%)=\frac{B-C}{B} \times 100 \%
$$

In which:

AR -- Antimicrobial rate (\%)

$\mathrm{B}$-- The average number of recovered bacteria in the blank control sample (CFU/piece)

$\mathrm{C}--$ The average number of recovered bacteria in the antibacterial sample (CFU/piece)

\section{Results And Discussion}

\subsection{Morphology and chemical composition of pretreated bamboo}


Bamboo is principally consisted of parenchyma and fiber, whose cell wall is mainly composed of cellulose microfibrils embedded in a matrix composed of lignin and hemicellulose. Here, an efficient pretreatment method of bamboo was established by delignification collaborating with carboxymethylation, in which delignification could increase the porosity of bamboo templates and facilitate the permeation of precursor solution, and carboxymethylation could improve the attachment of MOF on bamboo surface. As control, individual pretreatment of delignification or carboxymethylation were also performed. To investigate the influence of pretreatment on morphology and chemical composition of bamboo, the SEM images and FTIR spectra of natural bamboo and pretreated bamboo DB, CB and DCB were obtained. As shown in Fig. 1b, $c$, d, the hierarchically organized cell structure of DB, CB and DCB is well preserved. However, images of the cell corner (Fig. 1j, $k, I)$ revealed that the delignification or carboxymethylation pretreatment removed the innermost surface layer of the parenchyma cell walls.

Delignification is effective to increase the porosity of bamboo. After delignification, nano-scale pore and multilayer cell wall structure appeared in the cell wall and middle lamellae (Fig. 1j, I), suggesting a higher porosity. And the parenchyma cell surface of DB and DCB (Fig. 1f, h) is smoother than that of natural bamboo (Fig. 1e), due to highly ordered cellulose of the microfibrils exposed after lignin removal (Chen et al. 2020). From a macroscopic view in Fig. $1 \mathrm{~m}$, the original yellowish bamboo became bleached (DB) after delignification, indicating successful removal of the dark-colored lignin with the colorless polysaccharides exposed (Guan et al. 2018). The delignification treatment was further identified by FTIR, the characteristic peaks of lignin at 1655, 1600, 1512, 1458 and $834 \mathrm{~cm}^{-1}$ disappeared in DB (Fig. 1n).

To enhance the bonding strength between MOF199 and bamboo, carboxyl groups were introduced to the bamboo surface by carboxymethylation. Remarkably, the increase of bands at $1594 \mathrm{~cm}^{-1}$ in CB indicated that the active carboxyl group was successfully introduced into the bamboo surface by carboxymethylation. Meanwhile, the hemicelluloses (mannan and xylan) and some lignin-like polyphenols in the innermost surface layer were removed by the alkali treatment (Kim et al. 2012), as the entire absence at $1736 \mathrm{~cm}^{-1}$ (hemicellulose-related peaks) and significant decrease at $1245 \mathrm{~cm}^{-1}$ (hemicellulose and lignin-related peaks) were found in FTIR spectra of CB. These results are in good agreement with those from the research of carboxymethylation of European beech (Fagus sy/vatica) (Tu et al. 2020). According to previous research, alkali treatment of bamboo can also improve the surface roughness of bamboo (Costa et al. 2017), which is conducive to the attachment of MOF onto bamboo surface.

To facilitate the introduction of carboxyl groups, collaboration of delignification and carboxymethylation treatment of bamboo were used. Delignification increases the surface porosity of the bamboo, exposed the cellulose in the cell wall, thus facilitate carboxymethyl reactions. As noted, a new large wide peak within $1540-1650 \mathrm{~cm}^{-1}$ appeared in $\mathrm{DCB}$, which was attributed to the $\mathrm{C}=0$ stretching vibration in the introduced carboxyl groups (Duan et al. 2019b). Meanwhile, the characteristic peaks of lignin and hemicellulose $\left(1729,1655,1512,1458,1245\right.$ and $\left.834 \mathrm{~cm}^{-1}\right)$ in DCB disappeared in FTIR results. SEM 
images showed that several folds appeared in the parenchyma cell wall of DCB, accompanied with hollow of the cell wall corner (Fig. 1d, h, I), resulting from the loss of hemicellulose and lignin.

\subsection{Tailoring growth of MOF199 on Bamboo 3.2.1. In-situ growth of MOF199 on pretreated bamboo}

SEM images of MOF grown on parenchyma and fiber cell surface in pretreated bamboo were shown in Fig. 2 and Fig. S1. On MOF199/B, only loose and small-sized MOF199 crystals were observed (Fig. 2a, e and Fig. S1a, e). On MOF199/DB, uniform crystals with octahedral shape and relatively big size were found (Fig. 2b, f and Fig. S1b, f). And on MOF199/CB, large numbers of MOF199 with relatively small size distributed uniformly (Fig. 2c, g and Fig. S1c, g). Furthermore, a much denser MOF199 crystal was found on MOF199/DCB (Fig. 2d and Fig. S1d), and magnified image (Fig. 2h and Fig. S1h) revealed that the crystal size on MOF199/DCB was the smallest among the three pretreated bamboo samples, around 0.3$1.2 \mathrm{~nm}$ (Fig. S2).

The EDS spectra of four kinds of MOF199 coated bamboo and the natural bamboo were presented in Fig. 2a, b, c, d and Fig. S3, respectively. Elemental analysis results also demonstrated that the copper content of MOF199/DCB (11.1\%) was higher than MOF199/CB (8.5\%) and MOF199/DB (6.0\%), while MOF199/B has a minimum copper content of $0.5 \%$, which is consistent with SEM results and our prediction. Figure 3 shows the X-ray diffractograms of natural bamboo and MOF199 coated bamboo. Three diffraction peaks at $2 \theta$ of $16^{\circ}, 22.5^{\circ}$ and $35^{\circ}$ could be attributed to the (101), (002) and (040) crystal faces of cellulose, respectively. And the new peaks at $6.6^{\circ}, 9.5^{\circ}$ and $11.5^{\circ}$ corresponding to the (200), (220) and (222) crystal faces of MOF199, which are well consist with other literature (Lis et al. 2019; Loera-Serna et al. 2012; Wang et al. 2015). The XRD analysis indicated that the successful synthesis of MOF199 on bamboo. It should be noted that, MOF199/DCB sample displayed the sharpest characteristic peaks in all samples, suggesting that collaborating treatment of delignification and carboxymethylation is conducive for the crystal growth of MOF199 on the surface of bamboo. The above results indicate that pretreatment is essential for the in-situ growth of MOF199 on bamboo.

\subsubsection{Tailoring crystal size of MOF199 on bamboo}

The crystal size could also be controlled in our two-step synthesis process by adjusting the concentration of copper nitrate solution. Four gradient concentrations of copper nitrate solutions were used in the same procedure with the unified concentration of BTC solution and four different MOF199/DCB samples were obtained. SEM results and particle size measurements suggest the crystal size of MOF199 increased with increasing $\mathrm{Cu}^{2+}$ ion concentration (Fig. 4 and Fig. S4). Besides, the EDS analysis revealed that the Cu content of MOF199/DCB samples increased with added of $\mathrm{Cu}^{2+}$ ion concentration in the prepared solution (Table S1). Similarly, the same increase trend was observed in the XRD (Fig. S5) and FTIR spectra (Fig. S6) for the MOF199 characteristic peaks. 


\subsection{Interaction analysis between MOF199 and bamboo}

FTIR was used to investigate the interaction between MOF199 and bamboo cell wall after delignification/carboxymethylation, and the spectra are shown in Fig. 5. The possible interaction between MOF199 and bamboo is through the coordination of copper (II) ions and carboxyl group. The peaks at $730,761,1375$ and $1450 \mathrm{~cm}^{-1}$ in MOF coated bamboo were in strong consistency with MOF199 (Lange and Obendorf 2015; Song et al. 2011). Compared with natural bamboo, the new peak of $1648 \mathrm{~cm}^{-1}$ in MOF199/B replaced the original peak of $1653 \mathrm{~cm}^{-1}$ ( $C=0$ groups of lignin structure), which is attributed to the absorption band of carboxyl group in MOF199 (Abbasi et al. 2012; Abdelhameed et al. 2016; Küsgens et al. 2009).

Compared with DB samples, the $C=0$ peak of carboxyl group in MOF199/DB shift from $1635 \mathrm{~cm}^{-1}$ (Fig. 1n) to $1643 \mathrm{~cm}^{-1}$ (Fig. 5a), resulting from the interaction between MOF199 and bamboo through the coordination of carboxyl group from hemicellulose and $\mathrm{Cu}^{2+}$ (Abdelhameed et al. 2016). Similarly, the bands at $1642,1640 \mathrm{~cm}^{-1}$ in MOF199/CB and MOF199/DCB also exhibit similar trend of shifting (Fig. 5a), compared with the $\mathrm{C}=0$ peak of $-\mathrm{COO}^{-}$in $\mathrm{CB}\left(1594 \mathrm{~cm}^{-1}\right), \mathrm{DCB}\left(1599 \mathrm{~cm}^{-1}\right)$ samples (Fig. 1n), respectively. And the absorption band shift can attribute to the changes in the metal-carboxylate interaction from $\mathrm{COO}^{-}-\mathrm{Na}^{+}$to $\mathrm{COO}^{-}-\mathrm{Cu}^{2+}$ (Tu et al. 2020). With the increase of carboxyl group (green boxed section in Fig. $1 \mathrm{n}$ ) of the pretreated bamboo (DB, CB, DCB), the $\mathrm{COO}^{-}-\mathrm{Cu}^{2+}$ characteristic absorption band around $1648 \mathrm{~cm}^{-1}$ in MOF199 would shift to a lower wavenumber in MOF199/DB, MOF199/CB, MOF199/DCB samples (Fig. 5b). This shift demonstrated that MOF199 would anchor onto the pretreated bamboo via forming carboxyl-copper (II) complex.

The strong interaction between MOF199 and the introduced carboxyl groups in the pretreated bamboo was verified by ultrasonic desorption test. Results shown, after $20 \mathrm{~min}$ of sonication of the aqueous solution, only trace amounts of MOF199 remained on the surface of the bamboo prepared by the deposition method (Fig. S7a). In comparison, after treated in the same ultrasonic condition, a large amount of MOF199 still remain on the surface of MOF199/DCB (Fig. S7b). In summary, FTIR results and ultrasonic desorption test demonstrated there were strong interactions between the pretreated bamboo and MOF199, which is beneficial to the anchoring of MOF on bamboo substrate.

\subsection{Growth mechanism of MOF199 on bamboo}

In our synthesis route, the growth of MOF199 here was a separated two-step process, including adsorption of copper (II) ions and desorption-nucleation process. In the first step, the adsorption of $\mathrm{Cu}^{2+}$ is initiated after immersing bamboo in copper nitrate trihydrate, which is mainly divided into two forms: weak adsorption and strong adsorption. Weak adsorption refers to the $\mathrm{Cu}^{2+}$ ions are physically adsorbed in hierarchical bamboo surface. Strong adsorption refers to the binding between $\mathrm{Cu}^{2+}$ ions and strong polar groups of cellulose units, carboxylic acid of hemicellulose or phenolic hydroxyl groups and aromatic esters of lignin (Hoffmann et al. 2008; Rowell 1984). In the second step, after placing the Cu- 
adsorbed bamboo blocks into BTC solution, the adsorbed $\mathrm{Cu}^{2+}$ ion with weak interactions will desorb in the solution. And the polydentate ligand, BTC would capture the free $\mathrm{Cu}^{2+}$ ions and form molecule clusters. Meanwhile, the carboxyl-copper (II) complex on pretreated bamboo would act as nucleation site and allow the in-situ MOF199 growth by attracting free ions and clusters in solution.

The cell wall of bamboo is mainly composed of lignin, cellulose and hemicellulose, and the formation mechanism of MOF199 on pretreated bamboo with different functional group fractions is revealed by Fig. 6. The carbonyl or carboxylic functions of lignin may explain why natural bamboo show a slightly affinity toward MOF199 crystals (Küsgens et al. 2009; Liu 2007). After delignification, hemicellulose of DB was exposed which facilitate the coordination with $\mathrm{Cu}^{2+}$ for the following MOF growth, as most of the carboxyl groups in bamboo came from hemicellulose such as glucuronic acid (Michell et al. 1965). Carboxymethylation of natural bamboo alone can also promote MOF attachment by introducing active carboxyl groups in the phenolic hydroxyl of lignin, and alcohol of cellulose (Konduri et al. 2015). Collaboration of delignification and carboxymethylation would introduce large numbers of carboxyl groups in cellulose of DCB, provided enough active sites for coordinating $\mathrm{Cu}^{2+}$ thus formed a dense and evenly distributed MOF coating. However, the large number of carboxyl-copper (II) complex would initiate the rapid nucleation of MOF, which lead to a quick precursor consumption and relatively small-sized MOF crystals on bamboo surface (Fig. 2h) (Su et al. 2019).

The order of immersion in copper nitrate or BTC solution was found to be another critical factor for the growth of MOF199 on bamboo surface by the two-step manufacturing process. In our hypothesis, the initial absorption of $\mathrm{Cu}^{2+}$ on pretreated bamboo was critical for the following MOF growth. By exchanging the order of immersion of the two precursor solutions, the sample was prepared as rMOF/DCB. As expected, few crystals were found on rMOF/DCB surface with a different truncated octahedral morphology (Fig. S8). XRD and FTIR results confirmed those crystals exhibit the same characteristic peaks as MOF199 (Fig. S5 and Fig. S6). According to the XPS data, the Cu $2 p_{3 / 2}$ spectrum of MOF199/DCB (Fig. 7a) located three peaks at 935.2, 940.2 and 944.1, all corresponding to Cu-O in MOF199 (Li et al. 2014). While the asymmetrical Cu 2 $p_{3 / 2}$ peak of rMOF/DCB splitted into two peaks, the emerging stronger characteristic peak at $932.6 \mathrm{eV}$ is attributed to $\mathrm{Cu}-\mathrm{O}$ in carboxyl-copper (II) complex and the week characteristic peaks at $934.8 \mathrm{eV}$ belong to MOF199 (Fig. 7b) (Lemaire et al. 2016; Chawla et al. 1992; Senthil Kumar et al. 2013; Zhong 1989). XPS results suggested the rMOF/DCB sample adsorbed a large amount of $\mathrm{Cu}^{2+}$ ion by carboxyl group and only a small amount of them eventually formed MOF199 crystals. The results further demonstrated the attachment of $\mathrm{Cu}^{2+}$ ion on the modified bamboo could serve as nucleation sites for the formation of MOF199 crystals, which is the key to prepare of uniform MOF layers.

\subsection{Antibacterial property of MOF199 coated bamboo}

Escherichia coli is a common bacterium that endangers human health. The antibacterial activity testing results against $E$. coli are shown in Fig. 8. The pristine bamboo showed very low antibacterial activities, 
as for it contains natural antibacterial substances (Afrin et al. 2012). By contrast, the surviving bacterial colonies on the plate significantly decreased in MOF199 coated samples. The antibacterial property of MOF199 coated samples is ranked by antibacterial ratio (AR) in a decreasing order: MOF199/DCB (91.4\%), MOF199/CB (69.8\%), MOF199/DB (64.9\%), MOF199/B (55.6\%). Particularly, the MOF199/DCB resulted the lowest surviving colonies, suggesting the uniform and well-dispersed dense MOF199 coatings on bamboo would lead to a better antibacterial property. According to previous studies, the particle size and shape appear to be the most significant variables determining the antibacterial activity

of solids. And decreasing particle size might be beneficial because it results in considerable enhancement of the surface area, as well as the increased density of edge and corner sites on the surfaces of nanoparticles (Wyszogrodzka et al. 2016). Therefore, the tailoring growth of MOF199 including crystal size and amount is of great significance for the optimal antibacterial properties of woody materials.

\section{Conclusions}

In this work, the in-situ growth of MOF199 on bamboo surface was tailored via pretreatment and a green two-step synthesis route. Results shown the collaboration of delignification and carboxymethylation pretreatment of bamboo facilitated to form a dense and durable MOF199 layers, which exhibited excellent antibacterial activity against Escherichia coli (E. coli). In addition, the quantity of MOF199 increased with the increase of introduced carboxyl groups, and the crystal size of MOF199 increased with increase of the concentration of copper solution. Particularly, the formation of carboxyl-copper (II) complex served as nucleation sites was found to be a critical factor for the in-situ growth of MOF199 on bamboo surface. This study provides an optimized strategy for preparing a MOF/woody composites with great potential in various functions.

\section{Declarations}

\section{Author Contributions}

Minglei Su: Methodology, Investigation, Writing - Original Draft. Rong Zhang: Software, Formal analysis, Writing - Review \& Editing, Project administration, Funding acquisition. Jingpeng Li: Software, Formal analysis. Xiaobei Jin: Resources. Xiaofeng Zhang: Data Curation. Daochun Qin: Supervision, Project administration.

\section{Conflicts of Interest}

The authors declare no conflicts of interest.

\section{Acknowledgements}

The work was financially supported by the National Natural Science Foundation of China (Grant No. 31901377) and the Fundamental Research Funds for International Center for Bamboo and Rattan (No. 1632019016). 


\section{References}

Abbasi AR, Akhbari K, Morsali A (2012) Dense coating of surface mounted CuBTC Metal-Organic Framework nanostructures on silk fibers, prepared by layer-by-layer method under ultrasound irradiation with antibacterial activity. Ultrason Sonochem 19:846-852.

https://doi.org/10.1016/j.ultsonch.2011.11.016

Abdelhameed RM, Abdel-Gawad H, Elshahat M, Emam HE (2016) Cu-BTC@cotton composite: design and removal of ethion insecticide from water. RSC Adv 6:42324-42333.

https://doi.org/10.1039/c6ra04719j

Afrin T, Tsuzuki T, Kanwar RK, Wang X (2012) The origin of the antibacterial property of bamboo. J Textile I 103:844-849. https://doi.org/10.1080/00405000.2011.614742

Chen C, Li Z, Mi R, Dai J, Xie H, Pei Y (2020) Rapid processing of whole bamboo with exposed, aligned nanofibrils toward a high-performance structural material. ACS Nano 14(5):5194-5202.

https://doi.org/10.1021/acsnano.9b08747

Duan C, Meng J, Wang X, Meng X, Sun X, Xu Y (2018) Synthesis of novel cellulose-based antibacterial composites of Ag nanoparticles@ Metal-Organic Frameworks@ carboxymethylated fibers. Carbohyd Polym 193:82-88. https://doi.org/10.1016/j.carbpol.2018.03.089

Duan C, Liu C, Meng X, Lu W, Ni Y (2019a) Fabrication of carboxymethylated cellulose fibers supporting Ag NPs@MOF-199s nanocatalysts for catalytic reduction of 4-nitrophenol. Appl Organomet Chem 33:e4865. https://doi.org/10.1002/aoc.4865

Duan C, Meng X, Liu C, Lu W, Liu J, Dai L (2019b) Carbohydrates-rich corncobs supported Metal-Organic Frameworks as versatile biosorbents for dye removal and microbial inactivation. Carbohydr Polym 222:115042. https://doi.org/10.1016/j.carbpol.2019.115042

Emam HE, Saleh NH, Nagy KS, Zahran MK (2016) Instantly AgNPs deposition through facile solventless technique for poly-functional cotton fabrics. Int J Biol Macromol 84:308-318.

https://doi.org/10.1016/j.ijbiomac.2015.12.042

Guan H, Cheng Z, Wang X (2018) Highly compressible wood sponges with a spring-like lamellar structure as effective and reusable oil absorbents. ACS Nano 12:10365-10373.

https://doi.org/10.1021/acsnano.8b05763

Guo J, Rennhofer H, Yin Y, Lichtenegger HC (2016) The influence of thermo-hygro-mechanical treatment on the micro- and nanoscale architecture of wood cell walls using small- and wide-angle X-ray scattering. Cellulose 23:2325-2340. https://doi.org/10.1007/s10570-016-0982-2

He S, Chen C, Chen G, Chen F, Dai J, Song J (2020) High-performance, scalable wood-based filtration device with a reversed-tree design. Chem Mater 32:1887-1895. 
https://doi.org/10.1021/acs.chemmater.9b04516

Hoffmann SK, Goslar J, Ratajczak I, Mazela B (2008) Fixation of copper-protein formulation in wood: Part 2. Molecular mechanism of fixation of copper(II) in cellulose, lignin and wood studied by EPR. Holzforschung 62:300-308. https://doi.org/10.1515/hf.2008.032

Jin R, Bian Z, Li J, Ding M, Gao L (2013) ZIF-8 crystal coatings on a polyimide substrate and their catalytic behaviours for the Knoevenagel reaction. Dalton Trans 42:3936-3940. https://doi.org/10.1039/c2dt32161k

Kim JS, Awano T, Yoshinaga A, Takabe K (2012) Ultrastructure of the innermost surface of differentiating normal and compression wood tracheids as revealed by field emission scanning electron microscopy. Planta 235:1209-1219. https://doi.org/10.1007/s00425-011-1569-7

Küsgens P, Siegle S, Kaskel S (2009) Crystal growth of the Metal-Organic Framework $\mathrm{Cu}_{3}(\mathrm{BTC})_{2}$ on the surface of pulp fibers. Adv Eng Mat 11:93-95. https://doi.org/10.1002/adem.200800274

Lange LE, Obendorf SK (2015) Functionalization of cotton fiber by partial etherification and selfassembly of polyoxometalate encapsulated in $\mathrm{Cu}_{3}(\mathrm{BTC})_{2}$ metal-organic framework. ACS Appl Mater Interfaces 7:3974-3980. https://doi.org/10.1021/am506510q

Laurila E, Thunberg J, Argent SP, Champness NR, Zacharias S, Westman G, Öhrström L (2015) Enhanced synthesis of Metal-Organic Frameworks on the surface of electrospun cellulose nanofibers. Adv Eng Mater 17:1282-1286. https://doi.org/10.1002/adem.201400565

Lemaire PC, Zhao J, Williams PS, Walls HJ, Shepherd SD, Losego MD (2016) Copper benzenetricarboxylate Metal-Organic Framework nucleation mechanisms on metal oxide powders and thin films formed by atomic layer deposition. ACS Appl Mater Interfaces 8:9514-9522. https://doi.org/10.1021/acsami.6b01195

Li J, Su M, Wang A, Wu Z, Chen Y, Qin D, Jiang Z (2019) In situ formation of Ag nanoparticles in mesoporous $\mathrm{TiO}_{2}$ films decorated on bamboo via self-sacrificing reduction to synthesize nanocomposites with efficient antifungal activity. Int J Mol Sci 20:5497 https://doi.org/10.3390/ijms20215497

Li J, Wu Z, Bao Y, Chen Y, Huang C, Li N (2017) Wet chemical synthesis of ZnO nanocoating on the surface of bamboo timber with improved mould-resistance. J Saudi Chem Soc 21:920-928. https://doi.org/10.1016/j.jscs.2015.12.008

Li Y, Wang LJ, Fan HL, Shangguan J, Wang H, Mi J (2014) Removal of sulfur compounds by a copperbased Metal Organic Framework under ambient conditions. Energ Fuel 29:298-304. https://doi.org/10.1021/ef501918f 
Lis MJ, Caruzi BB, Gil GA, Samulewski RB, Bail A, Scacchetti FAP (2019) In-situ direct synthesis of HKUST1 in wool fabric for the improvement of antibacterial properties. Polymers (Basel) 11:1-11. https://doi.org/10.3390/polym11040713

Liu YX (2007) Wooden resource materials. China Forestry Press, Beijing

Loera-Serna S, Oliver-Tolentino MA, de Lourdes López-Núñez M, Santana-Cruz A, Guzmán-Vargas A, Cabrera-Sierra R (2012) Electrochemical behavior of $\left[\mathrm{Cu}_{3}(\mathrm{BTC})_{2}\right]$ Metal-Organic Framework: The effect of the method of synthesis. J Alloy Compd 540:113-120. https://doi.org/10.1016/j.jallcom.2012.06.030

Ma K, Idrees KB, Son FA, Maldonado R, Wasson MC, Zhang X, et al. (2020) Fiber composites of MetalOrganic Frameworks. Chem Mater 32:7120-7140. https://doi.org/10.1021/acs.chemmater. 0c02379

Ma S, Zhang M, Nie J, Yang B, Song S, Lu P (2018) Multifunctional cellulose-based air filters with high loadings of Metal-Organic Frameworks prepared by in situ growth method for gas adsorption and antibacterial applications. Cellulose 25:5999-6010. https://doi.org/10.1007/s10570-018-1982-1

Michell AJ, Watson AJ, Higgins HG (1965) An infrared spectroscopic study of delignification of eucalyptus regnans. Tappi 48:520-532

Costa MME, Melo SLS, Santos JVM, Araújo EA, Cunha GP, Deus EP, Schmitt N (2017) Influence of physical and chemical treatments on the mechanical properties of bamboo fibers. Procedia Eng 200:457464. https://doi.org/10.1016/j.proeng.2017.07.064

Konduri MK, Kong F, Fatehi P (2015) Production of carboxymethylated lignin and its application as a dispersant. Eur Polym J 70:371-383. https://doi.org/10.1016/j.eurpolymj.2015.07.028

Nasruddin, Zulys A, Yulia F, Buhori A, Muhadzib N, Ghiyats M, Saha BB (2020) Synthesis and characterization of a novel microporous lanthanide based Metal-Organic Framework (MOF) using napthalenedicarboxylate acid. J Mater Res Technol 9:7409-7417.

https://doi.org/10.1016/j.jmrt.2020.05.015

Ren J, Musyoka NM, Langmi HW, Swartbooi A, North BC, Mathe M (2015) A more efficient way to shape Metal-Organic Framework (MOF) powder materials for hydrogen storage applications. Int J Hydrogen Energy 40:4617-4622. https://doi.org/10.1016/j.jhydene.2015.02.011

Rowell R (1984) The Chemistry of solid wood. American Chemistry Society, Washington, D. C.

Chawla SK, Sankarraman N, Payer JH (1992) Diagnostic spectra for XPS analysis of Cu-O-S-H compounds. J Electron Spectrosc 61:1-18. https://doi.org/10.1016/0368-2048(92)80047-c

Senthil Kumar R, Senthil Kumar S, Anbu Kulandainathan M (2013) Efficient electrosynthesis of highly active $\mathrm{Cu}_{3}(\mathrm{BTC})_{2}-\mathrm{MOF}$ and its catalytic application to chemical reduction. Micropor Mesopor Mat 168:5764. https://doi.org/10.1016/j.micromeso.2012.09.028 
Song J, Luo Z, Britt DK, Furukawa H, Yaghi OM, Hardcastle KI, Hill CL (2011) A multiunit catalyst with synergistic stability and reactivity: a polyoxometalate-metal organic framework for aerobic decontamination. J Am Chem Soc 133:16839-16846. https://doi.org/10.1021/ja203695h

Su M, Zhang R, Li H, Jin X, Li J, Yue X, Qin D (2019) In situ deposition of MOF199 onto hierarchical structures of bamboo and wood and their antibacterial properties. RSC Adv 9:40277-40285. https://doi.org/10.1039/c9ra07046j

Tu K, Puértolas B, Adobes-Vidal M, Wang Y, Sun J, Traber J (2020) Green synthesis of hierarchical MetalOrganic Framework/wood functional composites with superior mechanical properties. Adv Sci 1902897. https://doi.org/10.1002/advs.201902897

Wang C, Qian X, An X (2015) In situ green preparation and antibacterial activity of Copper-based MetalOrganic Frameworks/Cellulose Fibers (HKUST-1/CF) composite. Cellulose 22:3789-3797. https://doi.org/10.1007/s10570-015-0754-4

Wang Z, Hauser PJ, Laine J, Rojas OJ (2012) Multilayers of low charge density polyelectrolytes on thin films of carboxymethylated and cationic cellulose. J Adhes Sci Technol 25:643-660. https://doi.org/10.1163/016942410x525876

Wyszogrodzka G, Marszalek B, Gil B, Dorozynski P (2016) Metal-Organic Frameworks: mechanisms of antibacterial action and potential applications. Drug Discov Today 21:1009-1018.

https://doi.org/10.1016/j.drudis.2016.04.009

Xu L, Xiong Y, Dang B, Ye Z, Jin C, Sun Q, Yu X (2019) In-situ anchoring of $\mathrm{Fe}_{3} \mathrm{O}_{4} / \mathrm{ZIF}-67$ dodecahedrons in highly compressible wood aerogel with excellent microwave absorption properties. Mater Design 182:108006. https://doi.org/10.1016/j.matdes.2019.108006

Zhang R, Li Y, He Y, Qin D (2020) Preparation of iodopropynyl butycarbamate loaded halloysite and its anti-mildew activity. J Mater Res Technol 9:10148-10156. https://doi.org/10.1016/ j.jmrt.2020.07.019

Zhong ZL (1989) XPS study of coordination of Cu(II) with 2-mercaptobenzothiazole. J Struct Chem 8:301-304. https://doi.org/10.14102/j.cnki.0254-5861.1989.04.010

\section{Figures}



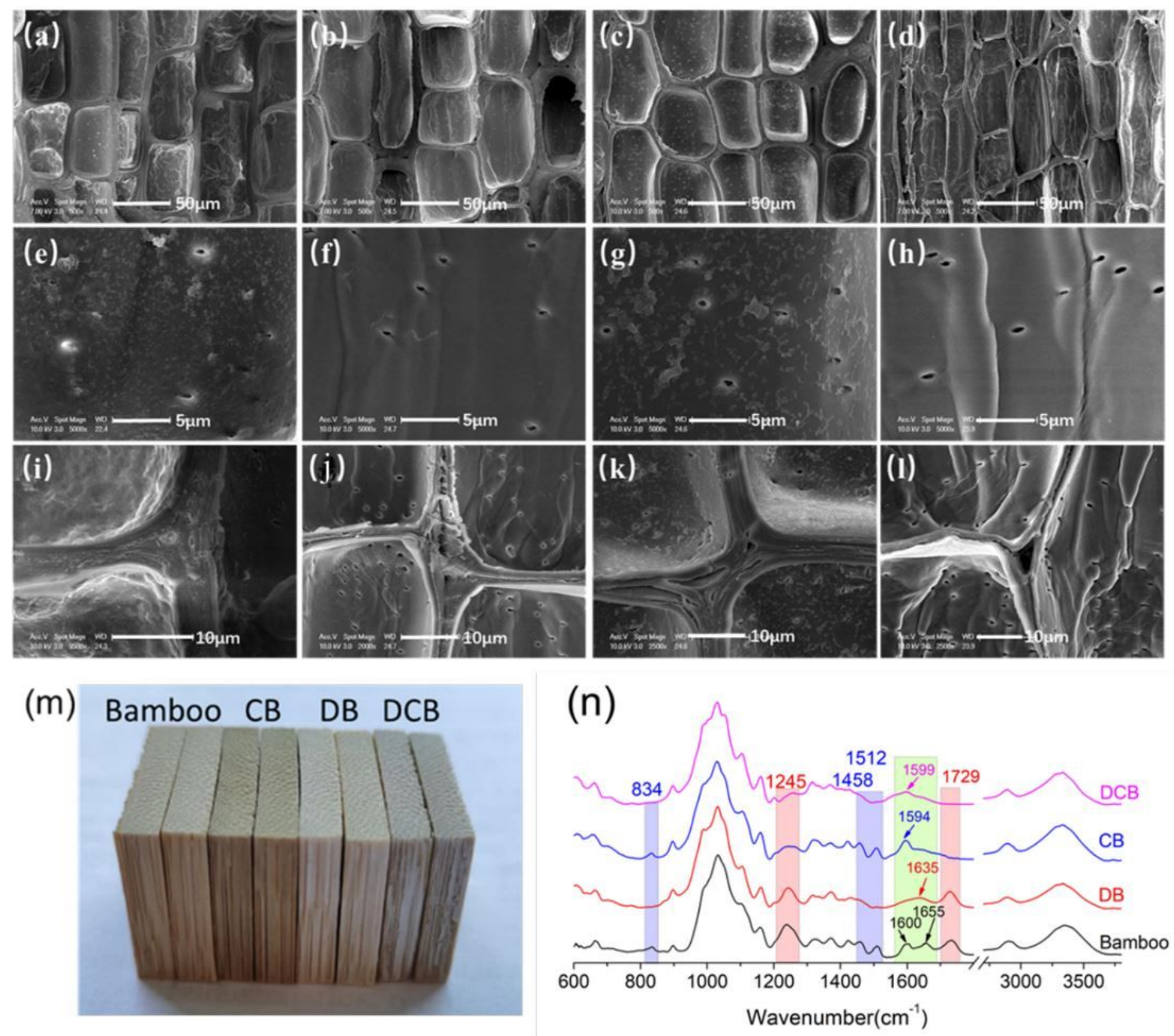

\section{Figure 1}

SEM images of natural bamboo (a, e, i) and pretreated bamboo DB (b, f, j), CB (c, g, k) and DCB (d, h, l); Optical images $(m)$ and ATR-FTIR spectra $(n)$ of natural bamboo and pretreated bamboo DB, CB and DCB. 

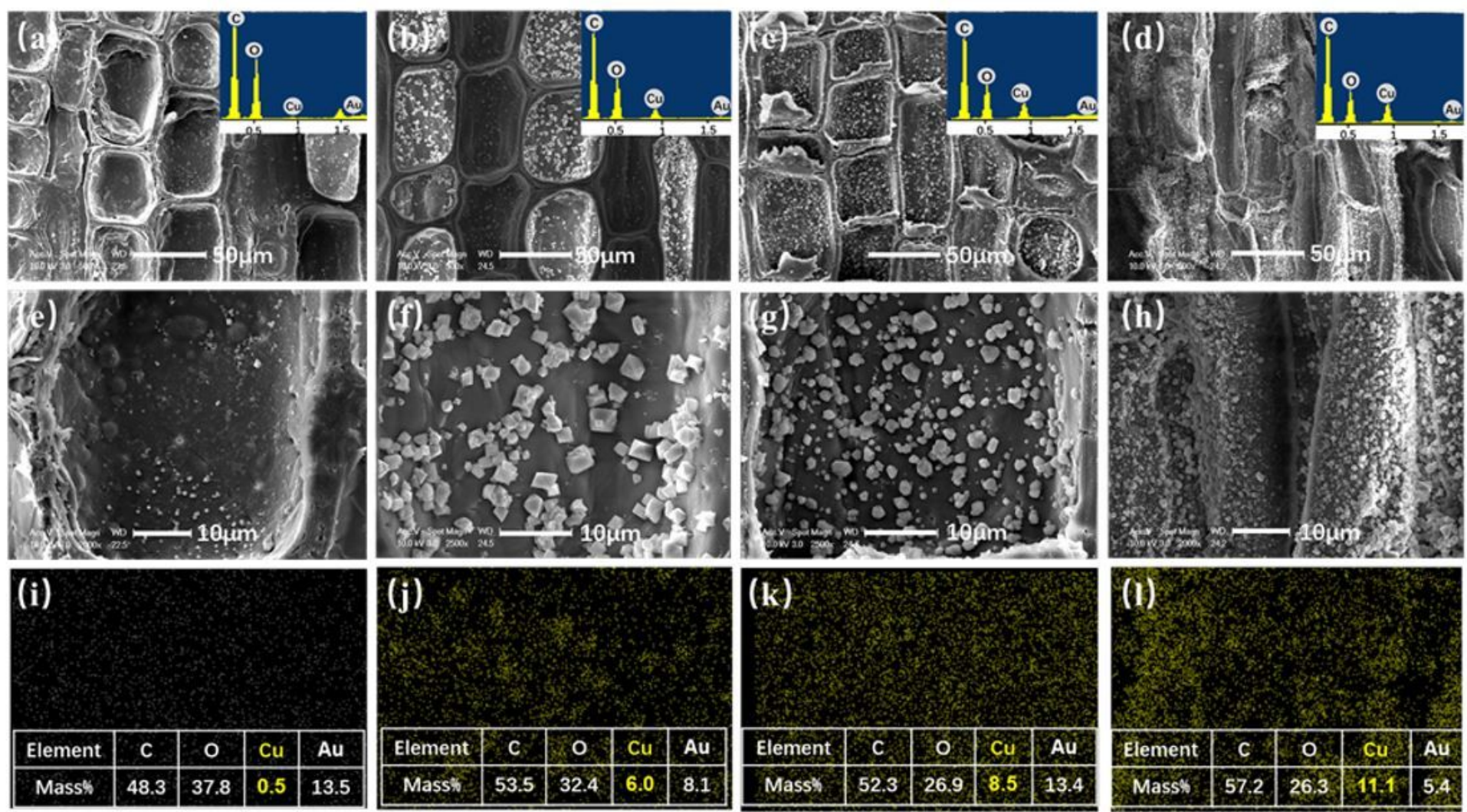

Figure 2

SEM and EDS images of parenchyma cell in MOF199/B (a, e, i), MOF199/DB (b, f, j), MOF199/CB (c, g, k) and MOF199/DCB (d, h, l). 


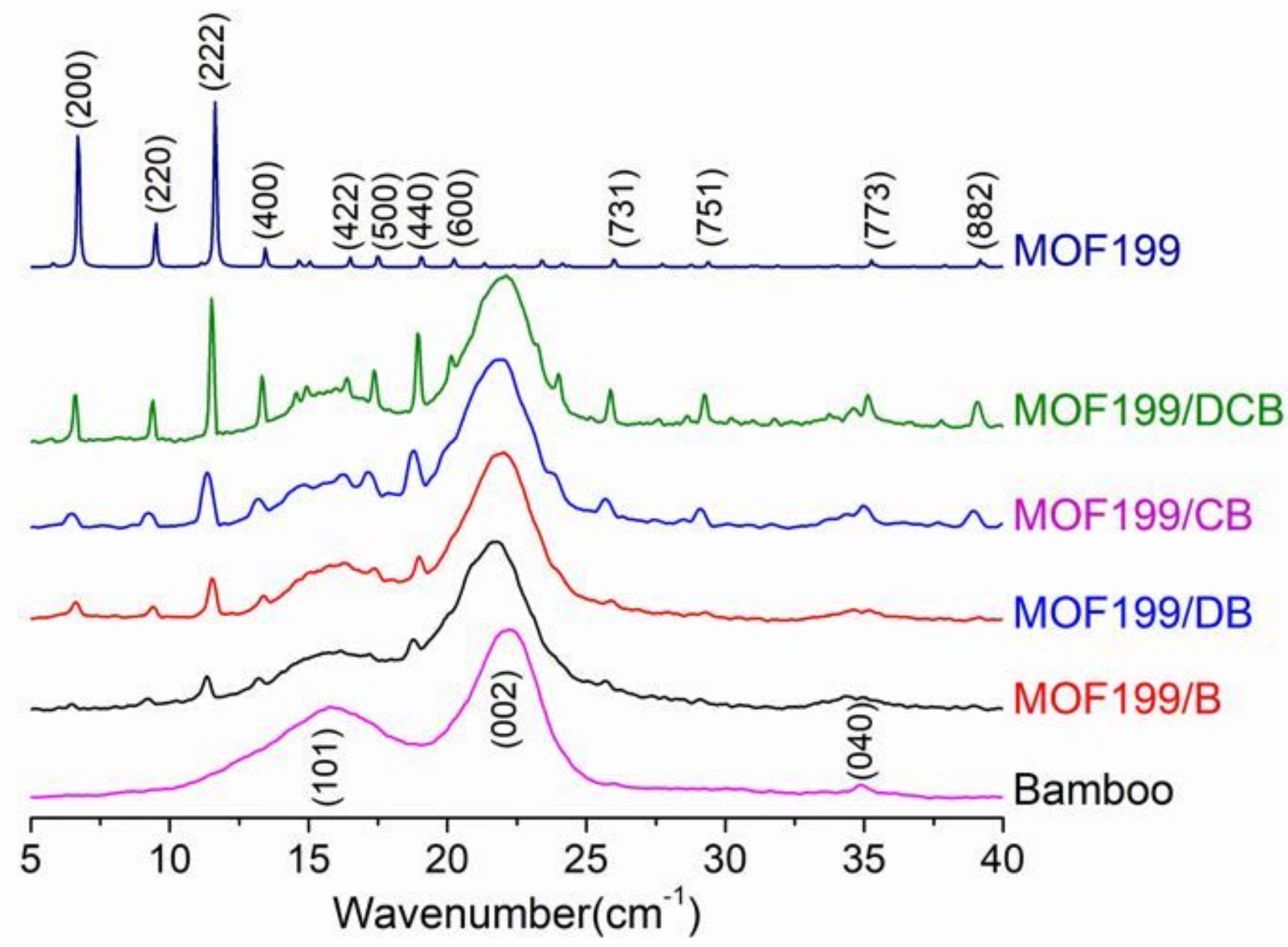

Figure 3

XRD spectra of simulated MOF199, natural Bamboo, MOF199/B, MOF199/DB, MOF199/CB and MOF199/DCB. 

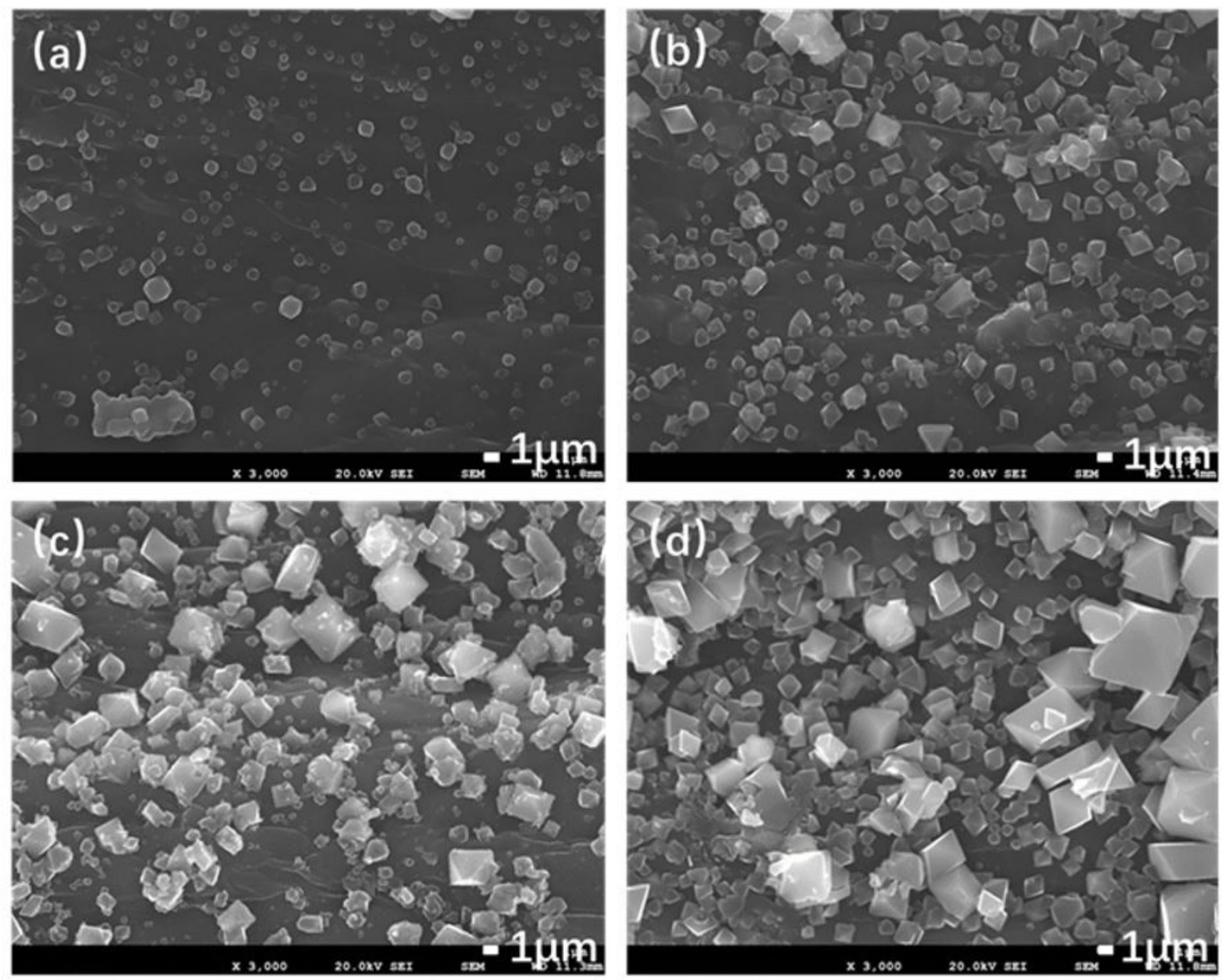

Figure 4

SEM images of MOF199/DCB-1 (a), MOF199/DCB-2 (b), MOF199/DCB-3 (c) and MOF199/DCB-4 (d). 

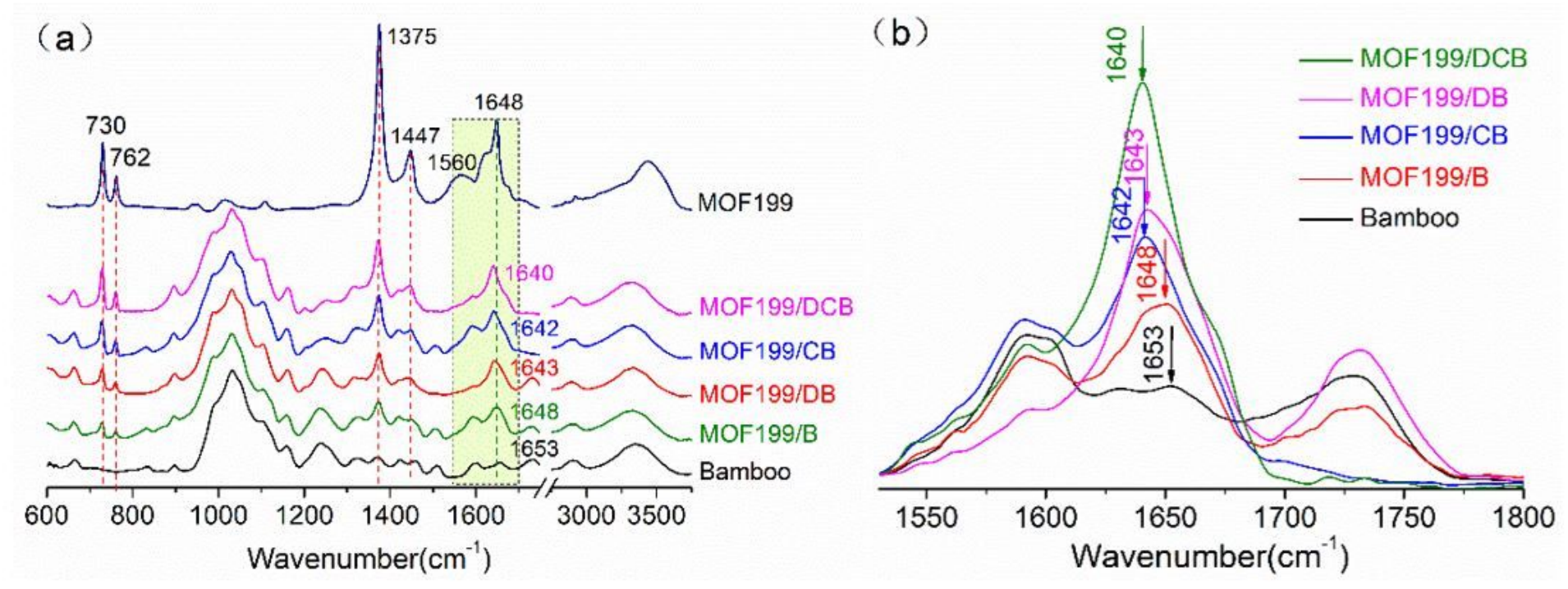

Figure 5

(a)ATR-FTIR spectra of natural Bamboo, MOF199/B, MOF199/DB, MOF199/CB, MOF199/DCB and MOF199. (b) Partial magnification of the green box portion of the ATR-FTIR spectrum in (a). 


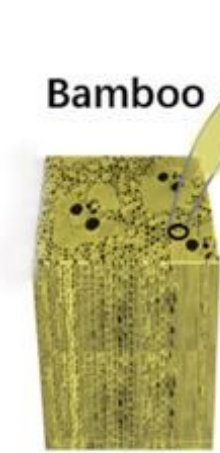

(2) Carboxymethylation

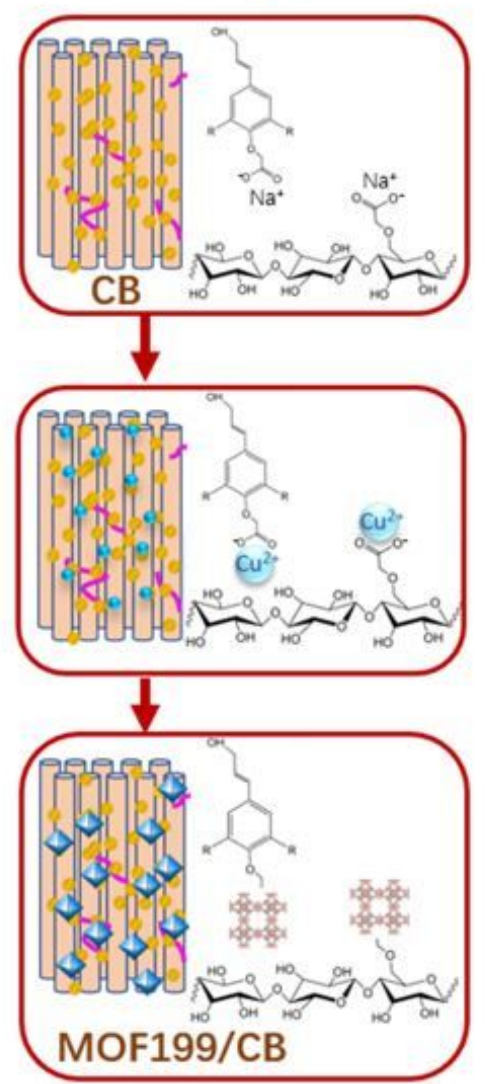

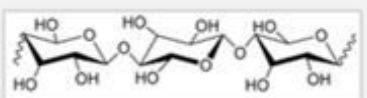

Cellulose

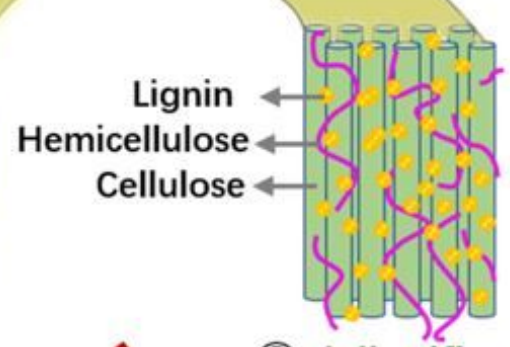

(3) delignification
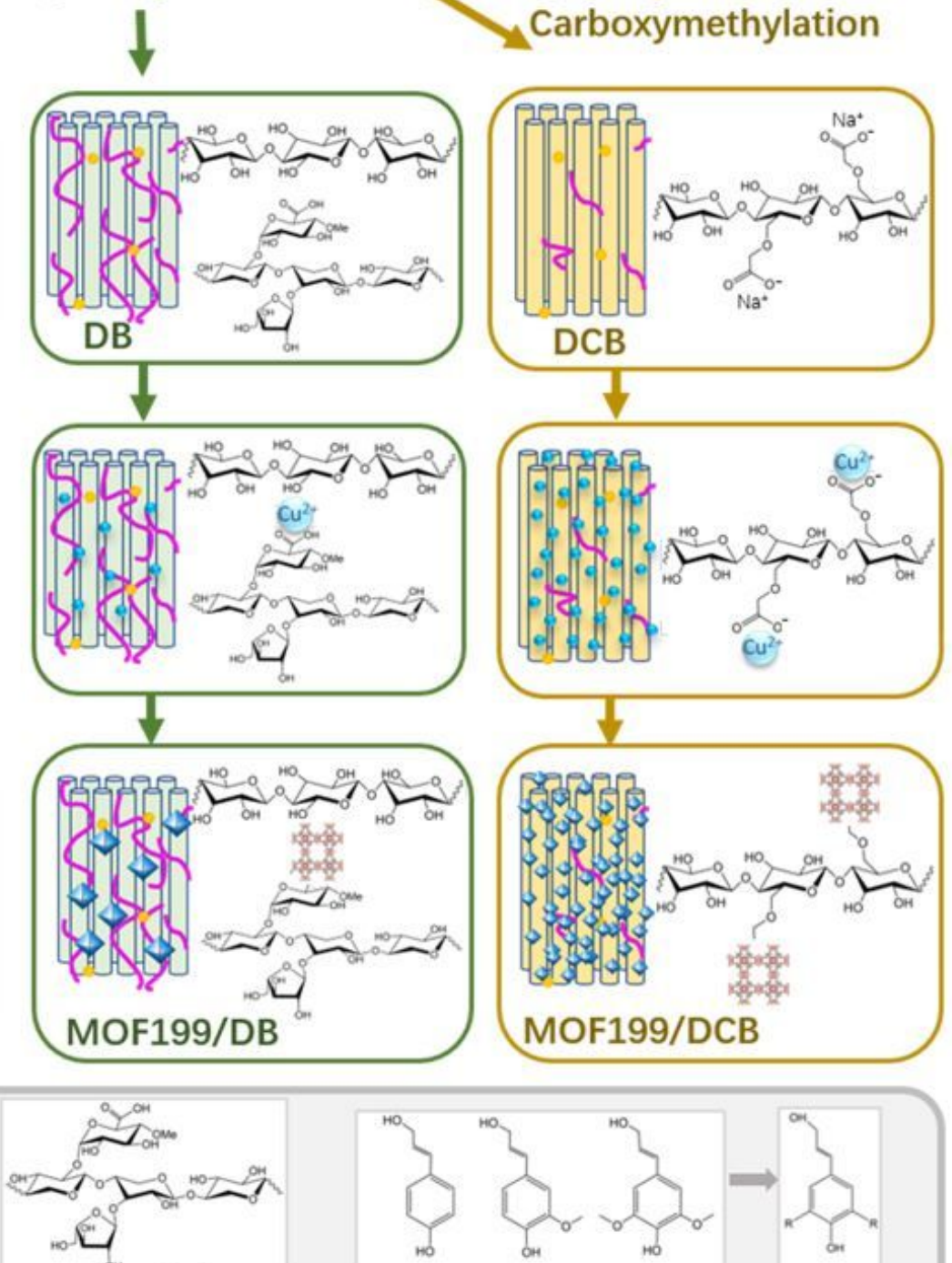

Hemicellulose

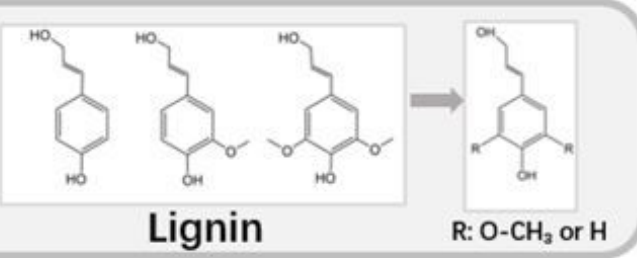

\section{Figure 6}

Sketches represent the growth mechanism of MOF199 on pretreated bamboo. 


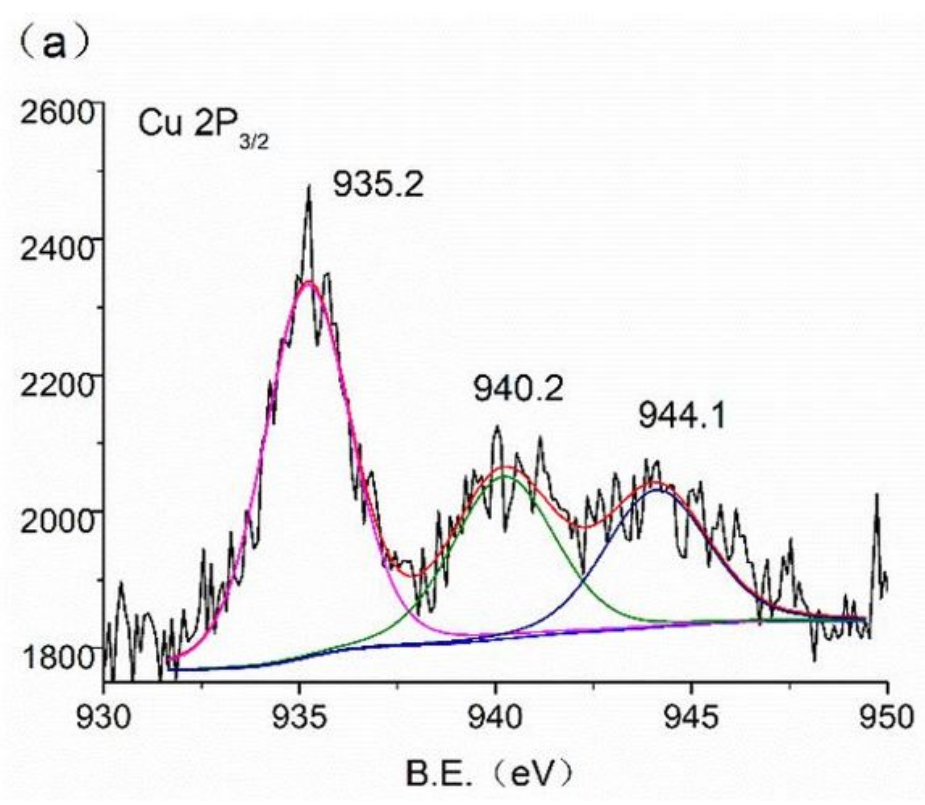

(b)

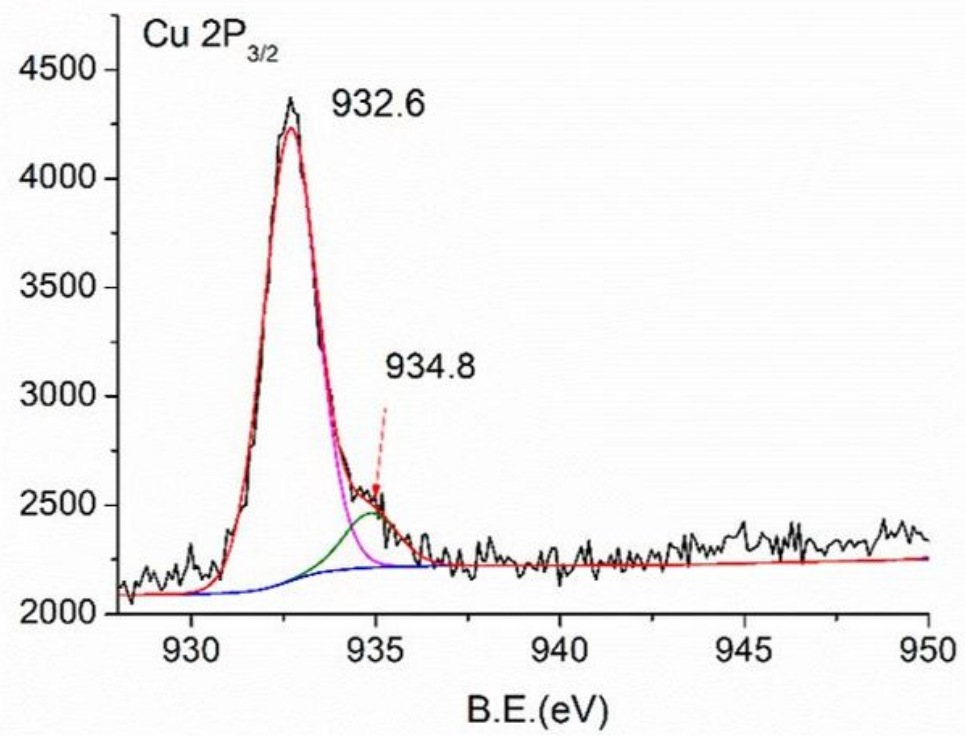

\section{Figure 7}

XPS spectra of MOF199/DCB (a) and rMOF199/DCB (b). 


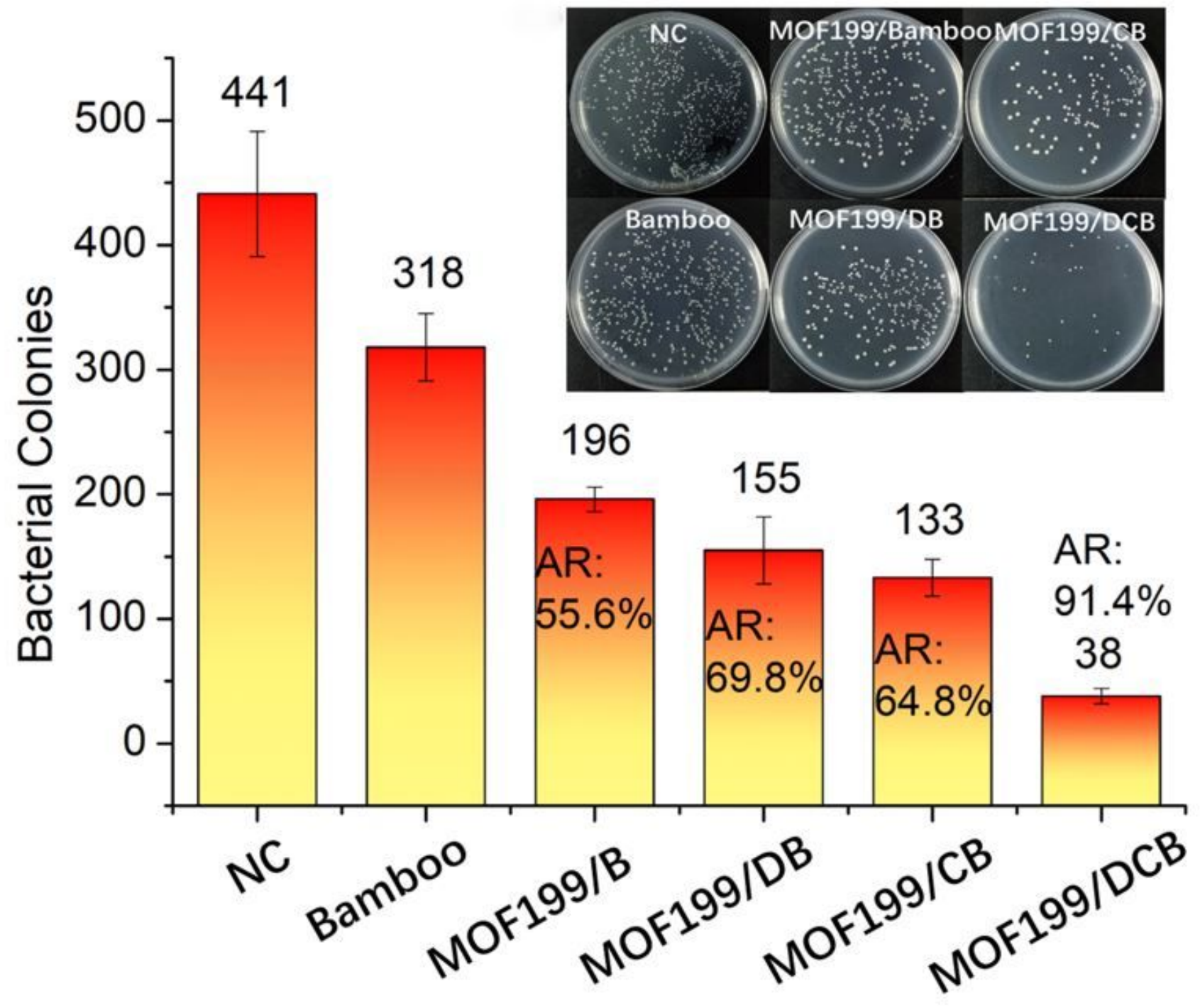

Figure 8

The number of E. coli colonies formed in antibacterial test of negative control (NC), natural bamboo, MOF199/B, MOF199/DB, MOF199/CB and MOF199/DCB and the antibacterial ratio of these samples. The inserted photos are bacterial colonies of $\mathrm{E}$. coli in antibacterial test.

\section{Supplementary Files}

This is a list of supplementary files associated with this preprint. Click to download.

- schematic1.jpg

- SupplementaryInformation.docx 